\title{
Effects of ubiquitin C-terminal hydrolase L1 deficiency on mouse ova
}

\author{
Sayaka Koyanagi ${ }^{1}$, Hiroko Hamasaki ${ }^{1}$, Satoshi Sekiguchi ${ }^{1}$, Kenshiro Hara ${ }^{2}$, Yoshiyuki Ishii ${ }^{1}$, \\ Shigeru Kyuwa ${ }^{1}$ and Yasuhiro Yoshikawa ${ }^{1,3}$ \\ Department of ${ }^{1}$ Biomedical Science and ${ }^{2}$ Veterinary Anatomy, Graduate School of Agricultural and Life Sciences, \\ The University of Tokyo, Yayoi 1-1-1, Bunkyo-ku, Tokyo 113-8657, Japan and ${ }^{3}$ Laboratory of Zoonoses, School of \\ Veterinary Medicine, Kitasato University, Towada, Aomori 034-8628, Japan
}

Correspondence should be addressed to S Kyuwa; Email: akyuwa@mail.ecc.u-tokyo.ac.jp

K Hara is now at Division of Germ Cell Biology, National Institute for Basic Biology, National Institutes for Natural Sciences, Okazaki 444-8787, Japan

\begin{abstract}
Maternal proteins are rapidly degraded by the ubiquitin-proteasome system during oocyte maturation in mice. Ubiquitin C-terminal hydrolase L1 (UCHL1) is highly and specifically expressed in mouse ova and is involved in the polyspermy block. However, the role of UCHL1 in the underlying mechanism of polyspermy block is poorly understood. To address this issue, we performed a comprehensive proteomic analysis to identify maternal proteins that were relevant to the role of UCHL1 in mouse ova using UCHL1-deficient gad. Furthermore, we assessed morphological features in gad mouse ova using transmission electron microscopy. NACHT, LRR, and PYD domain-containing (NALP) family proteins and endoplasmic reticulum (ER) chaperones were identified by proteomic analysis. We also found that the 'maternal antigen that embryos require' (NLRP5 (MATER)) protein level increased significantly in gad mouse ova compared with that in wild-type mice. In an ultrastructural study, gad mouse ova contained less ER in the cortex than in wild-type mice. These results provide new insights into the role of UCHL1 in the mechanism of polyspermy block in mouse ova.

Reproduction (2012) $143271-279$
\end{abstract}

\section{Introduction}

Maternal proteins are synthesized and degraded dynamically during oocyte maturation. Intracellular protein degradation plays important roles in modulating the levels of specific proteins and eliminating damaged proteins to achieve fertilization and early embryo development. The ubiquitin-proteasome system is a major pathway for selective intracellular protein degradation in ova. Ubiquitination of proteins is recognized to target proteins for degradation by proteasomes and for internalization into the lysosomal system. Deubiquitinating enzymes (DUBs) regulate ubiquitination and regenerate free ubiquitin after proteins have been targeted to the proteasome or lysosome.

While other DUB members are ubiquitously expressed, ubiquitin C-terminal hydrolase L1 (UCHL1), one of the DUBs, is selectively expressed in neurons and germ cells (Wilson et al. 1988, Wilkinson et al. 1989). Recent studies suggest that UCHL1 associates with monoubiquitin and prolongs the ubiquitin half-life in neurons (Osaka et al. 2003) and that UCHL1 regulates apoptosis in testicular germ cells (Kwon et al. 2004,
2005). However, the role of UCHL1 in ova is largely unknown. We previously reported that $\mathrm{UCHL} 1$ is exclusively localized on the plasma membrane of mouse ova and plays an important role in the polyspermy block (Sekiguchi et al. 2006). Polyspermic fertilization refers to the penetration of ova by two or more spermatozoa, resulting in the developmental failure of the zygote (Sun 2003). It is necessary to block polyspermy for successful fertilization. At the time of fertilization, polyspermy is prevented primarily by the zona pellucida (ZP) block (also known as the zona reaction) following cortical granule exocytosis (CGE) in mammalian ova (Hatanaka et al. 1992). Susor et al. (2010) showed that UCHL1 regulates CG reorganization and contributes to the ZP block using UCHL1 inhibitors. In contrast, 'gracile axonal dystrophy' (gad) female mice, which are autosomal recessive, spontaneous mutants carrying an intragenic deletion of the gene encoding UCHL1, show a significantly increased in vitro polyspermy rate and a decrease in litter size, even though gad mouse ova undergo a normal zona reaction (Saigoh et al. 1999, Sekiguchi et al. 2006). Thus, the role of 
UCHL1 in the mechanism of inhibiting polyspermy in mouse ova remains unclear.

To address these issues, we sought to identify the difference in protein expression induced by Uchl1 deletion, based on a comprehensive proteomic analysis using gad mice, and identified maternal-specific proteins and endoplasmic reticulum (ER) chaperones that were relevant to the role of UCHL1 in mouse ova. Further, we observed morphological changes in gad mouse ova using transmission electron microscopy (TEM). These findings have important implications for understanding the role of UCHL1 in mouse ova.

\section{Results}

\section{Normal expression of F-actin and cofilin in gad mouse ova}

F-actin is necessary for CGE, changes membrane structure at fertilization, and consequently blocks polyspermy of ova (Tsaadon et al. 2006). We investigated the protein expression and localization of F-actin and its depolymerizing factor, cofilin, in wild-type and gad mouse ova (Fig. 1). Cofilin belongs to a family of F-actin depolymerizing factors that are highly conserved throughout the animal kingdom. The cofilin protein severs actin filaments and promotes actin dynamics by accelerating the treadmilling of actin filaments, a process in which monomers are removed from the pointed end of the filaments and are added to the barbed end (Carlier et al. 1997). However, no difference in the protein level or localization was observed between the wild-type and gad mouse ova.

\section{Identification of differentially expressed ovum proteins by proteomic analysis}

A typical proteomic analysis involves three fundamental steps: 1) proteins of a complex mixture are separated and digested into peptide units, 2) peptide masses are determined using mass spectroscopy, and 3) proteins are identified by searching databases for matching peptides (Kirkpatrick et al. 2005). In this study, liquid chromatography-tandem mass spectrometry (LC-MS/ MS) was used. The list of proteins that were downregulated or upregulated with statistical significance (one-sided $P$ value $<0.025$ ) in gad mouse ova is presented in Table 1. ZP1 is a component of the ZP, consisting of three glycoproteins (ZP1, ZP2, and ZP3), and cross-links ZP2 and ZP3 (Wassarman \& Litscher 2008). TLE6 belongs to the Groucho/Tle superfamily of transcriptional corepressors that plays critical roles in a range of developmental processes (Bajoghli 2007, Buscarlet \& Stifani 2007). ENPL, HSPA5 (GRP78), and CALR are ER chaperones and regulators of the unfolded protein response (UPR) in the ER (Qiu \& Michalak 2009, Eletto et al. 2010, Pfaffenbach \& Lee 2011). NLRP14 (NALP14) is a member of the NALP family, which consists of 14 members. The family members have quite similar domain structures and expression during oogenesis and embryogenesis. Thus, they are assumed to have common functions during oocyte maturation and early embryo development (Zhang et al. 2008). However, at present, there is little information about NLRP14 and its function remains to be determined. In contrast, NLRP5 (NALP5), one of the NALP family members, has been well studied. Furthermore, the NLRP5 protein has many characteristics in common with UCHL1. Their expression levels and subcellular localization are strongly correlated throughout oogenesis and embryogenesis (Li et al. 2008, Ohsugi et al. 2008). NLRP5 localizes in the subcortex of ova and is excluded from the region of cell-cell contact at the two-cell stage. Correspondingly, UCHL1 shows the similar expression pattern in the ovum and at the two-cell stage (Fig. 2). Thus, in this study, we focused on the NLRP5 protein for its interesting similarities to UCHL1.

\section{Expression and localization of the NLRP5 protein in mouse ova}

We conducted a western blot analysis to confirm the expression levels of the NLRP5 protein in ova obtained from gad mice with those from wild-type mice. Levels of NLRP5 in gad mouse ova were significantly higher than those in wild-type mouse ova ( $P=0.022$; Fig. $3 \mathrm{~A}$ and $\mathrm{B})$. Furthermore, to assess the relationship between UCHL1 and NLRP5, we analyzed their localization in wild-type and gad mouse ova. The two proteins colocalized on the plasma membrane and in the subcortex of wild-type

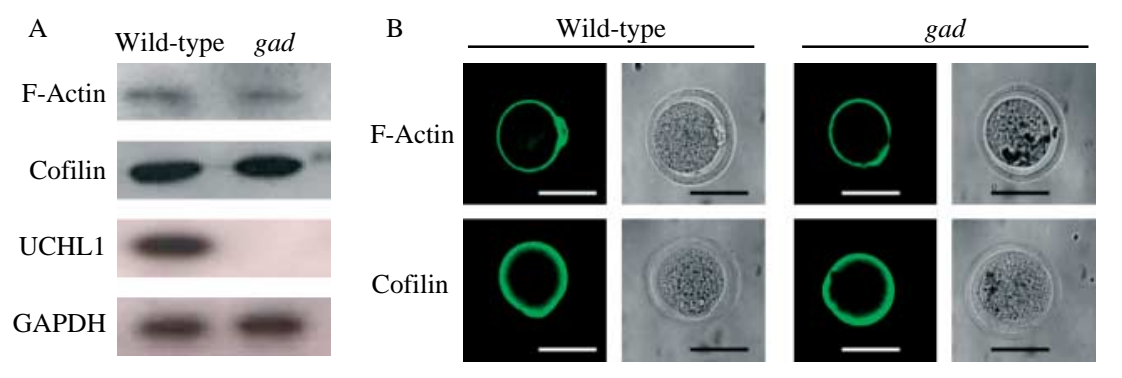

Figure 1 Expression and localization of F-actin and cofilin proteins in mouse ova. (A) Western blot analysis of F-actin, cofilin, ubiquitin C-terminal hydrolase L1 (UCHL1), and GAPDH in ova from wild-type $(n=6)$ and $\operatorname{gad}(n=7)$ mice. No significant difference was observed in the F-actin and cofilin protein levels. UCHL1 was not detected in gad mouse ova. (B) F-actin and cofilin immunoreactivity are seen on the plasma membrane of ova from wild-type and gad mice. Bars, $50 \mu \mathrm{m}$. 
Table 1 Differentially expressed oocyte proteins in wild-type and gad mice by liquid chromatography-mass spectrometry analysis.

\begin{tabular}{|c|c|c|c|}
\hline Identified proteins & $\begin{array}{l}\text { Molecular } \\
\text { weight } \\
(\mathrm{kDa})\end{array}$ & $\begin{array}{c}\text { Expression level } \\
\text { (wild-type (wt) } \\
\text { vs gad) }\end{array}$ & $\begin{array}{c}\boldsymbol{P} \text { value } \\
\text { (one-sided) }\end{array}$ \\
\hline $\begin{array}{l}\text { Zona pellucida sperm-binding } \\
\text { protein } 1 \text { precursor (ZP1) }\end{array}$ & 69 & wt $<$ gad & 0.022 \\
\hline $\begin{array}{l}\text { Transducin-like enhancer } \\
\text { protein } 6 \text { (TLE6) }\end{array}$ & 65 & wt $<$ gad & 0.025 \\
\hline Endoplasmin precursor (ENPL) & 92 & wt $<$ gad & 0.022 \\
\hline $\begin{array}{l}78 \text { kDa glucose-regulated } \\
\text { protein precursor (HSPA5) }\end{array}$ & 72 & $w t<\operatorname{gad}$ & 0.023 \\
\hline Calreticulin precursor (CALR) & 48 & wt $<$ gad & 0.002 \\
\hline $\begin{array}{l}\text { NACHT, LRR, and PYD } \\
\text { domain-containing } \\
\text { protein } 14 \text { (NLRP14) }\end{array}$ & 113 & wt $<$ gad & 0.023 \\
\hline $\begin{array}{l}\text { Ubiquitin C-terminal } \\
\text { hydrolase L1 (UCHL1) }\end{array}$ & 25 & wt $>$ gad & 0.002 \\
\hline
\end{tabular}

mouse ova (Fig. 4). However, the localization of NLRP5 in gad mouse ova was not different from that in wild-type mice (Fig. 4).

\section{Ultrastructural observations of gad mouse ova}

To assess whether gad mouse ova have a morphologically normal cortex structure, we analyzed them ultrastructurally by TEM (Fig. 5). Although basic structures such as CGs, microvilli, and cytoplasmic lattices (CPLs) were observed in both wild-type and gad mouse ova, there were no obvious structures that can be identified with ER cluster in the cortex of gad mouse ova.

\section{Discussion}

This study provided important findings on the role of UCHL1 in the mechanism of polyspermy block in mouse ova. It is necessary to block polyspermy for successful fertilization, which primarily involves a ZP block in mammalian ova. The ZP block comprises CGE and modification of the ZP so that the plasma membrane cannot support sperm binding by the enzymes released from CGs. F-actin regulates the movement of CGs toward the cortex during oocyte maturation and anchors them at the cortex (Connors et al. 1998). F-actin depolymerization occurs at CGE, and the protein level of F-actin decreases after fertilization (Eliyahu et al. 2005). We observed that the F-actin and cofilin protein expression levels and distribution on the plasma membrane were similar between the wild-type and gad mouse ova. We also found decreased F-actin protein levels, but no significant difference between the wildtype and gad mouse zygotes was observed after fertilization (data not shown). These results confirm our results of the CGE and ZP reaction in gad mouse ova (Sekiguchi et al. 2006). However, each protein is recognized differentially according to various posttranslational modifications, such as phosphorylation and ubiquitination (Kirkpatrick et al. 2005). In fact, cofilin proteins are thought to be regulated through phosphorylation and activated by dephosphorylation at the serine residue (Meberg \& Bamburg 2000). Thus, these findings suggest that cofilin proteins in gad mouse oocytes might be degenerated or modified differently from those in wild-type ova. Further experiments are needed to confirm this.

We then conducted a comprehensive proteomic analysis to identify any UCHL1-related proteins using gad mouse ova and identified NALP family proteins. The NALP family has 14 members with similar domain structures, and thus members are assumed to have common functions (Zhang et al. 2008). Almost all NALP family genes are expressed during oogenesis and embryogenesis (Zhang et al. 2008). We then focused on NLRP5 and confirmed protein expression and localization in wild-type and gad mice. The specificity and quantification of the LC-MS/MS method are greater than or equal to immunoassays including western blot and immunocytochemical staining. However, the high specificity enables us to reduce false-positive, but, on the other hand, it also reduces sensitivity (Kruse et al. 2008, Krone et al. 2010). Hence, this is the reason why NLRP5 was not detected by LC-MS/MS analysis in this study. The NLRP5 protein has many characteristics in common with UCHL1 (Sekiguchi et al. 2006, Ohsugi et al. 2008). First, UCHL1 and NLRP5 protein expression persist from immature oocytes in a primary follicle until the blastocyst stage.

Secondly, UCHL1 and NLRP5 may play an important role in oocyte maturation or embryogenesis because both gad and NLRP5-deficient females attain normal sexual maturity with intact ovarian folliculogenesis and the ability to ovulate fertilizable ova, but they have severe defects in reproduction. Thirdly, the most interesting analogy is the subcellular localization; neither protein is detected in the region of contact between the blastomeres, and they are restricted to the periphery through embryogenesis. This shared and unique expression pattern appears to indicate an interaction, such as regulation of NLRP5 protein levels by the ubiquitin-proteasome system including UCHL1. In fact, we found a significant increase in NLRP5 protein levels in gad mice with localization on the plasma membrane and subcortex.

The NLRP5 protein was identified abundantly and is an excellent candidate for a maternal-effect protein for the maturation and ovulation of ova (Zhang et al. 2009). The NLRP5 protein and transcript accumulate during oogenesis, and the transcript is almost completely degraded during meiotic maturation (Su et al. 2007, Li et al. 2008, Ohsugi et al. 2008). In contrast to the dramatic decrease in the transcript, the protein remains largely unchanged until the early blastocyst stage, suggesting that the protein level is properly regulated by degradation for the maintenance and control of 
A
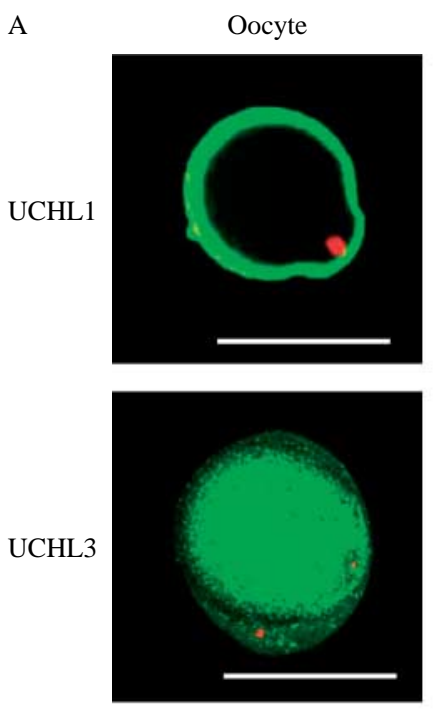

B
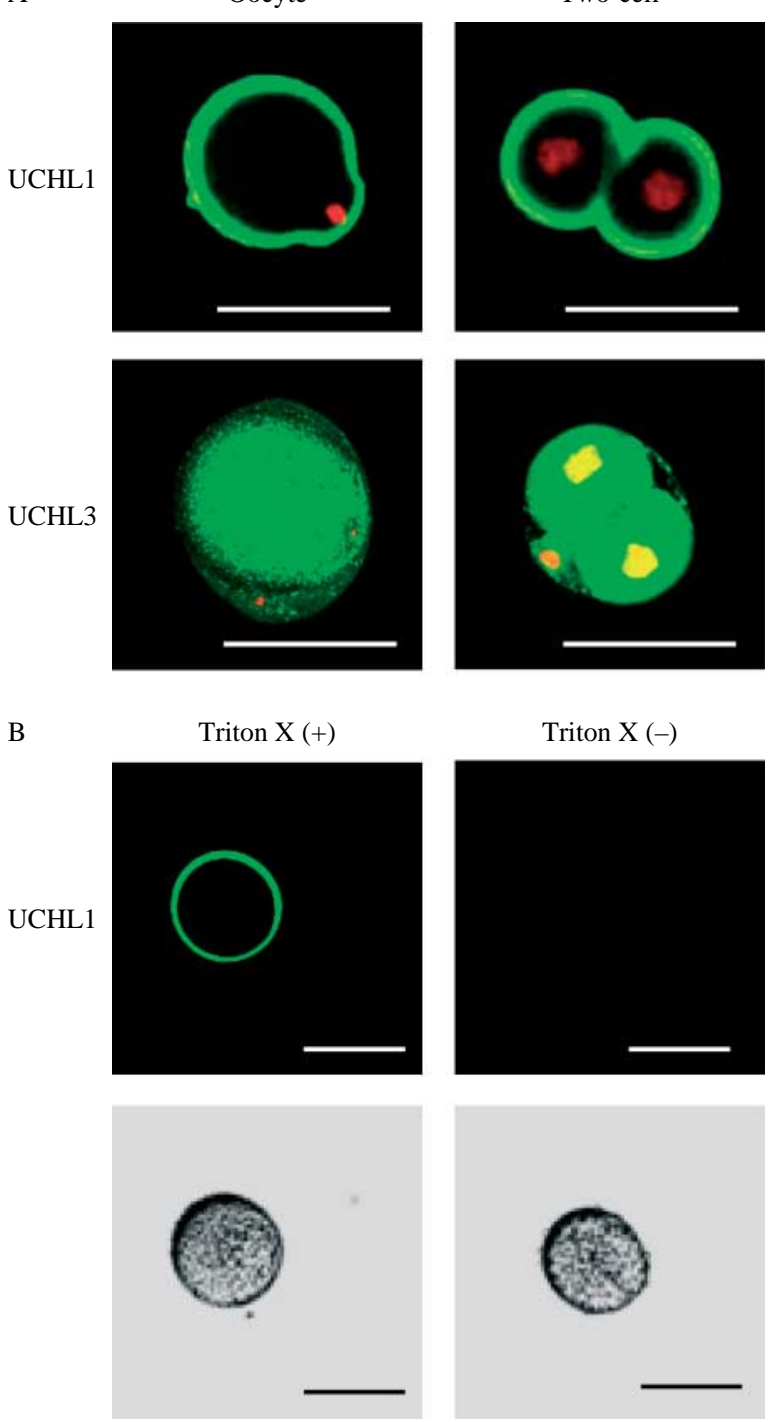

Figure 2 Localization of ubiquitin C-terminal hydrolase L1 (UCHL1) and UCHL3 in wild-type mouse ova. (A) UCHL1 immunoreactivity is seen on the plasma membrane of the ovum and at the two-cell stage. On the other hand, UCHL3, one of the DUBs, is seen in the cytoplasm of the ovum and at the two-cell stage. (B) While UCHL1 immunoreactivity is seen on the plasma membrane when treated with Triton X-100, it is not seen in the ova when not treated with Triton X-100. Bars, $50 \mu \mathrm{m}$.

maturation, fertilization, and early embryo development. Degradation of maternal proteins and transcripts is carried out rapidly in many organisms and plays a critical role in oocyte maturation. Most protein degradation is regulated by the ubiquitin-proteasome system and any impairment in degradation results in the failure of oocyte maturation (DeRenzo \& Seydoux 2004, Huo et al. 2004, Ryu et al. 2008, Beall et al. 2010). UCHL1 is essential for maintaining the ubiquitin-proteasome system and is abundantly expressed in mouse ova (Sekiguchi et al. 2006). Similarly, previous studies have identified UCHL1 as a maternal protein necessary for oocyte maturation
(Ellederova et al. 2004, Massicotte et al. 2006, Susor et al. 2007). Thus, a logical potential conclusion would be that the NLRP5 protein level is potentially regulated by the ubiquitin-proteasome system for oocyte maturation. In fact, ubiquitin mRNA levels are upregulated when the NLRP5 protein decreases during oogenesis and embryogenesis (Robert et al. 2002, Pennetier et al. 2006, Ohsugi et al. 2008). Furthermore, a UCHL1 inhibitor prevents germinal vesicle (GV) breakdown and the metaphase I-anaphase transition in porcine oocytes by downregulating the ubiquitin-proteasome system (Susor et al. 2007). Thus, excess NLRP5 protein resulting from downregulating the ubiquitin-proteasome system prevents complete oocyte maturation. Recent studies have reported that NLRP5 forms a subcortical maternal complex (SCMC) with maternally encoded proteins, an oocyte-specific binding protein of NLRP5 (FILIA), 'a factor located in oocytes permitting embryonic develop-

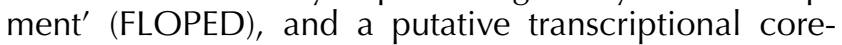
pressor (TLE6; Li et al. 2008, Ohsugi et al. 2008). Considering that TLE6 was significantly upregulated in gad ova (Table 1), it seems likely that SCMC of gad mouse ova had difficulty in regulating the component balance. Thus, further research is required to understand the relationship between maternal proteins and UCHL1 in mouse ova. Taken together, we hypothesized that gad mouse ova polyspermy is caused by oocyte maturation failure (Fig. 6).

To test this, we investigated whether gad mouse ova showed morphological characteristics of immaturity using TEM. As expected, the CG of gad mouse ova localized normally. This result provides further support for our previous work (Sekiguchi et al. 2006). Recent reports have shown that NLRP5 also localizes to the CPLs, and Mater ${ }^{t \mathrm{tm} / \mathrm{tm}}$ mouse ova lack CPLs (Kim et al. 2010, Tashiro et al. 2010). Unlike Nlrp5 hypomorphic mice, gad mouse ova containing excess NLRP5 protein showed normal CPLs. Interestingly, there were no obvious structures that can be identified with ER cluster in the cortex of gad mouse ova. The ER is a multifunctional and highly dynamic organelle involved in lipid and protein synthesis and is a major internal store of calcium ions that must be properly mobilized at fertilization (Baumann \& Walz 2001, Berridge 2002). It is well established that fertilization triggers an increase and oscillations in intracellular calcium concentration, resulting in the induction of CGE (Ducibella \& Fissore 2008). The mechanisms of intracellular calcium release from the ER develop during oocyte maturation, and an ER cluster appears in the cortex of mature mouse ova (Mehlmann et al. 1995). Cortical reorganization of the ER occurs in many species before fertilization, and the presence of ER cortical clusters is thought to result in a high susceptibility of ova to initiate calcium oscillations following sperm entry (Ducibella \& Fissore 2008). The sensitivity of the system to calcium release increases after maturation. A previous study reported differences 

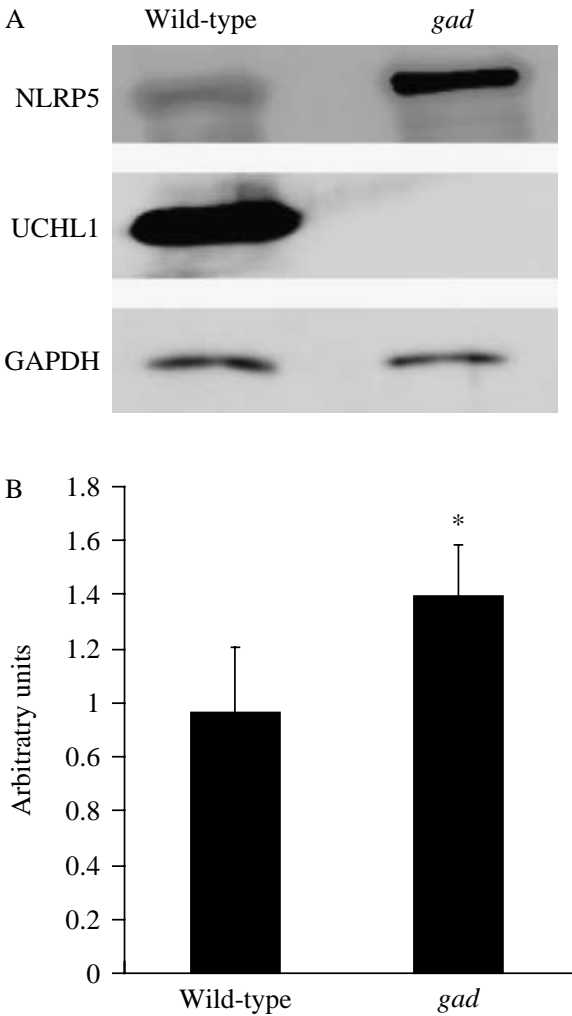

Figure 3 Expression of 'maternal antigen that embryos require' (NLRP5 (MATER)) and 'ubiquitin C-terminal hydrolase L1' (UCHL1) proteins in mouse ova. (A) Western blot analysis of NLRP5, UCHL1, and GAPDH in ova from wild-type $(n=5)$ and gad $(n=4)$ mice. UCHL1 was not detected in gad mouse ova. (B) NLRP5 protein levels in gad mouse ova were significantly higher than those in wild-type mice $(P=0.02)$. Bars represent mean \pm s.D. Significant difference $(P<0.05)$ is indicated by an asterisk.

regarding fertilization-induced calcium signals between immature oocytes and ova (Stricker 1999). Immature oocytes have less ER in the cortex compared with ovulated ova, and calcium release in response to fertilization is substantially less and slower than mature ova, resulting in polyspermy (Ducibella et al. 1993). Polyspermy in immature oocytes was attributed to complete failure or a CGE delay following calcium signaling (Ducibella et al. 1993). These findings suggest that polyspermy observed in gad mouse ova may have been caused by a delay in CGE resulting from its immaturity, although CGE and ZP react (Fig. 6). Furthermore, a recent study showed that calcium signaling plays a role in establishing the membrane block to polyspermy using ZP-free mouse ova (McAvey et al. 2002). Thus, gad mouse ova polyspermy was also considered to be due to the failure of the membrane block (Fig. 6). However, the mechanism for a polyspermy membrane block is largely unknown. Further examination is required to confirm this.

Additionally, we identified ER chaperones (ENPL, HSPA5, and CALR) by proteomic analysis, which were upregulated significantly in gad mouse ova. These chaperone proteins are constitutively expressed in the $E R$, and expression is regulated by the UPR, known as the ER signal transduction pathway (Rutkowski \& Hegde 2010). Unfolded or malfolded proteins accumulating in the ER (ER stress) activate the UPR, which degrades the proteins via ER-associated degradation involving the ubiquitin-proteasome system (Yoshida 2007). Given that the ubiquitin-proteasome system is impaired due to the lack of UCHL1 in gad mouse ova, ER chaperones may be upregulated by the accumulation of abnormal proteins. Indeed, ER stress is induced by a UCHL1 inhibitor in neuronal cells (Tan et al. 2008). Thus, it is also possible that ER stress following an excess of abnormal protein causes ER dysfunction, and gad mouse ova showed an impaired polyspermy block (Fig. 6). However, further investigations are necessary to reveal the relationship between polyspermy and a UCHL1 deficiency in ova.

In conclusion, we identified UCHL1-related proteins by proteomic analysis using gad mouse ova. We also found that the NLRP5 protein level increased significantly in gad mouse ova vs wild-type mice. Furthermore, we observed that gad mouse ova contained less ER in the cortex. These results suggest that UCHL1 regulates the NLRP5 protein level in mouse ova maturation.
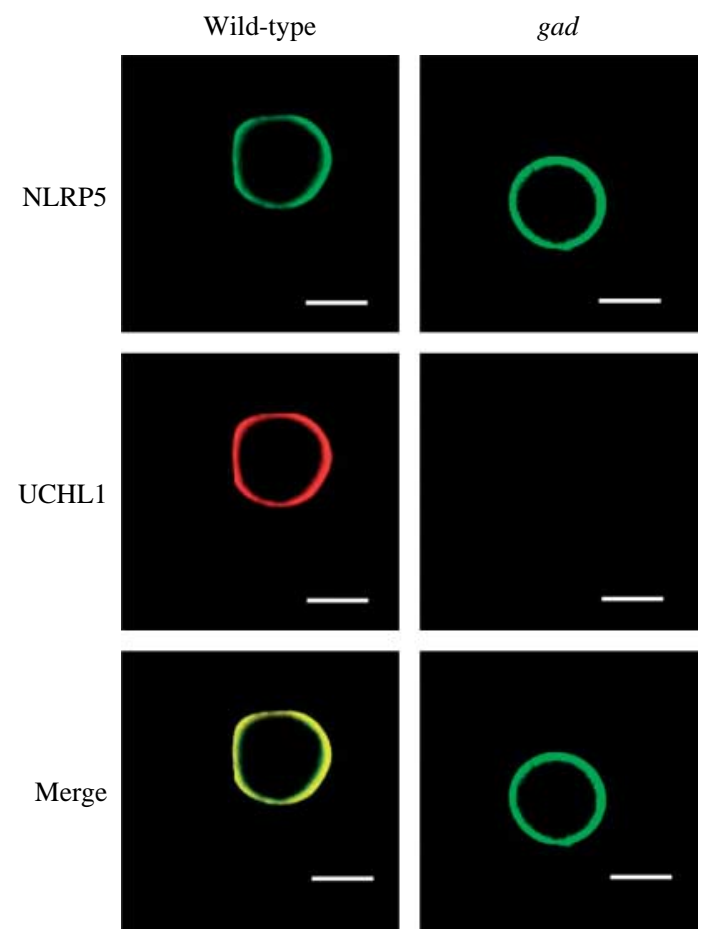

Figure 4 Localization of 'maternal antigen that embryos require' (NLRP5 (MATER)) and 'ubiquitin C-terminal hydrolase L1' (UCHL1) proteins in mouse ova. Immunocytochemical analysis of NLRP5 and UCHL1 in ova from wild-type and gad mice. NLRP5 immunoreactivity is seen on the plasma membrane of ova from wild-type and gad mice. NLRP5 and UCHL1 are co-localized on the plasma membrane of ova from wild-type mice. Bars, $50 \mu \mathrm{m}$. 

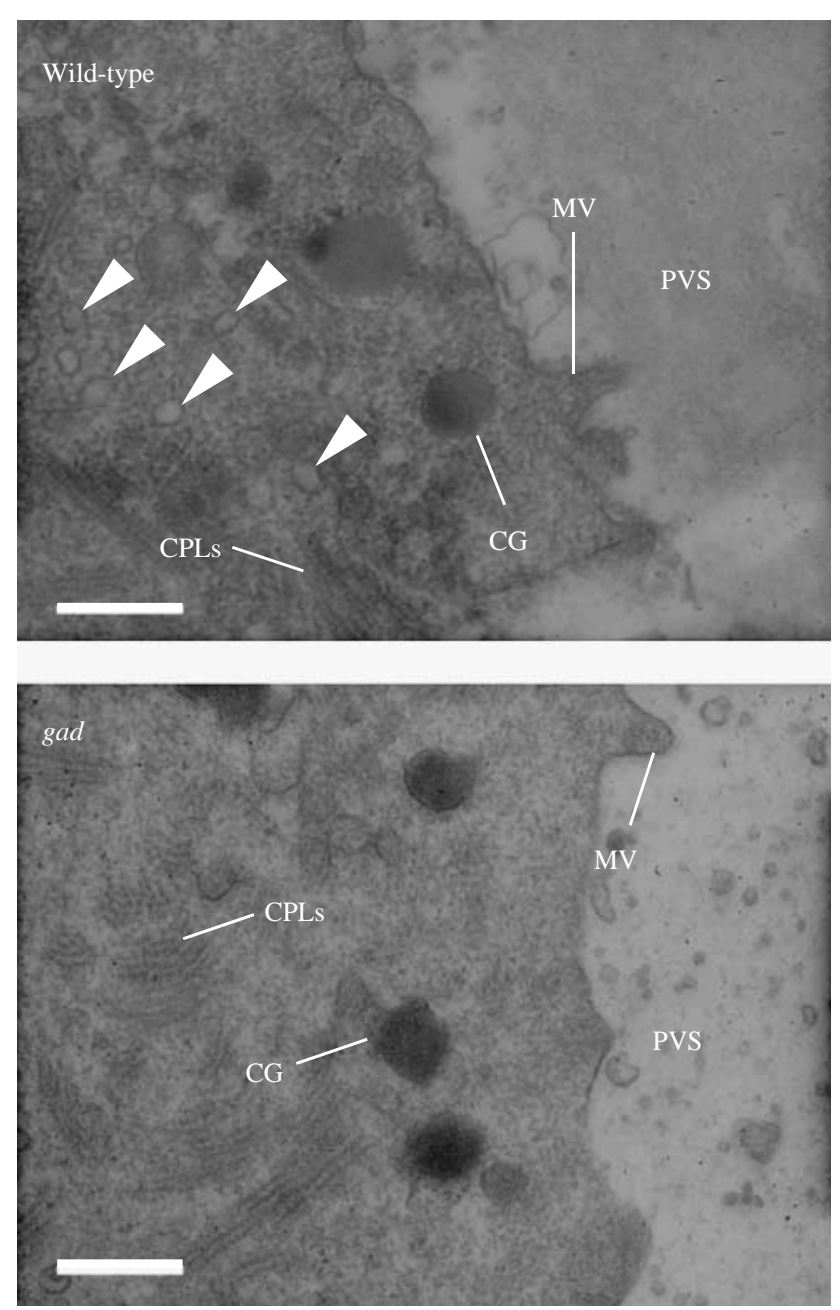

Figure 5 Ultrastructural study of ova from wild-type and gad mice by transmission electron microscopy. Basic cellular structures and cortical granule (CG), microvilli (MV), cytoplasmic lattices (CPLs), and perivitelline space (PVS) are observed in wild-type and gad mice. gad ova appear to have less endoplasmic reticulum (ER) than wild-type mice (arrowheads). Bars, $0.5 \mu \mathrm{m}$.

\section{Materials and Methods}

\section{Animals}

Nine-week-old BDF1 and gad female mice were used in this study. BDF1 mice were purchased from Nihon SLC, Inc. (Hamamatsu, Japan). The gad mouse is an autosomal recessive mutant obtained by cross-breeding CBA and RFM mice (Saigoh et al. 1999). The gad line is maintained at our institute. Genotyping was conducted using PCR with the following primers: F1, 5'-AGCTTGGAGCCTGTGGTTTCAACTC-3'; R1， 5'-TGGCAGCATCCTGAAAAGGAGAGAGGTG-3'; R2, 5'-TACAGATGGCCGTCCACGTTGTTGA-3', as described elsewhere (Sakurai et al. 2008).

Animal care and handling were conducted in accordance with institutional regulations. These experiments were approved by the Animal Care and Use Committee of the Graduate School of Agricultural and Life Sciences, The University of Tokyo.

\section{Ova collection}

Female mice were superovulated with i.p. injections of $5 \mathrm{IU}$ equine chorionic gonadotropin for $48 \mathrm{~h}$, followed by $5 \mathrm{IU}$ human chorionic gonadotropin (hCG). Ovulated ova were collected from the ampullae of the oviducts using the scratching method $15 \mathrm{~h}$ after hCG injection and placed in $400 \mu \mathrm{l}$ droplets of HTF medium containing $0.4 \mathrm{mg} / \mathrm{ml}$ BSA. Then, $0.05 \%$ hyaluronidase was added to the medium to remove the cumulus cells.

\section{Liquid chromatography-tandem mass spectrometry}

The capillary reversed-phase $\mu \mathrm{LC}-\mathrm{MS} / \mathrm{MS}$ system (ZAPLOUS System, AMR, Inc., Tokyo, Japan) consisted of a Paradigm MS4 dual solvent delivery system (Michrom BioResources, Inc., Auburn, CA, USA) for HPLC, an HTC PAL autosampler (CTC Analytics, Zwingen, Switzerland), and Finnigan LTQ linear ion-trap mass spectrometers (ITMS, Thermo Fischer, San Jose, CA, USA) equipped with XYZ nanoelectrospray ionization (NSI) sources (AMR, Inc.). We used three wild-type mice and three gad mice for LC-MS/MS analysis and collected 20 ova from each mouse. Samples (20 ova each) were prepared using digestion solution to a final volume of $20 \mu \mathrm{l}$. Then, digested samples of $1.0 \mu \mathrm{l}$ (equivalent to 1 -ovum proteins) were automatically injected into a peptide L-trap column (Chem. Eval. Res. Inst., Saitama, Japan) on an injector valve for concentrating and desalting. Sample handling and injection were conducted with the HTC-PAL autosampler (CTC Analytics).

An injection volume was $1 / 20$ equivalents. After desalting with $0.1 \%$ TFA (trifluoro acetic acid; aq.) containing $2 \%$ acetonitrile, the sample was loaded into a MAGIC C18 capillary reversed-phase column $(3 \mu \mathrm{m}, 200 \AA, 150 \times 0.2 \mathrm{~mm}$ i.d.; Michrom BioResources, Inc.) for separation. The mobile phase was as follows: A) $98 \% \mathrm{H}_{2} \mathrm{O} / 2 \% \mathrm{CH}_{3} \mathrm{CN} / 0.1 \% \mathrm{HCOOH}$ and B) $10 \% \quad \mathrm{H}_{2} \mathrm{O} / 90 \% \quad \mathrm{CH}_{3} \mathrm{CN} / 0.1 \% \mathrm{HCOOH}$. The gradient conditions in the chromatographic run were as follows: $\mathrm{B}$ from $5 \%$ B (0 min) to 55\% B (100 min), and then 95\% B (1 min), 95\% $\mathrm{B}(9 \mathrm{~min}), 5 \% \mathrm{~B}(1 \mathrm{~min})$, and 5\% B (9 min). Effluent at a flow rate of $0.5 \mathrm{ml} / \mathrm{min}$ was introduced into the mass spectrometer by the NSI interface via an injector valve with the L-trap column and the reversed phase (RP) column. The NSI needle (150/20 FortisTip; OmniSeparo-TJ, Hyogo, Japan), connected directly to the reverse-phase column outlet, was used as the NSI interface and the voltage was $2.0 \mathrm{kV}$, while the capillary was heated to $200{ }^{\circ} \mathrm{C}$. No sheath or auxiliary gas was used.

Furthermore, the mass spectrometer was operated in a datadependent acquisition mode in which MS acquisition with a mass range of $450-1800 \mathrm{~m} / \mathrm{z}$ was automatically switched to MS/MS acquisition under the automated control of Xcalibur Software (Thermo Fisher, San Jose, CA, USA). The MS measurement sequence was Full MS (enhanced/profile), MS/MS (Top1: normal/centroid), MS/MS (Top2: normal/centroid), and MS/MS (Top3: normal/centroid). The parent ions were subjected to MS/MS scans with an isolation width of $2.0 \mathrm{~m} / \mathrm{z}$; the activation amplitude parameter was set at $35 \%$. The trapping time was $50 \mathrm{~ms}$ under the auto gain control mode. Data were acquired using the dynamic mass exclusion windows that had an exclusion of $2.0 \mathrm{~min}$ duration and an exclusion mass width of -0.5 and +1.5 Da. 


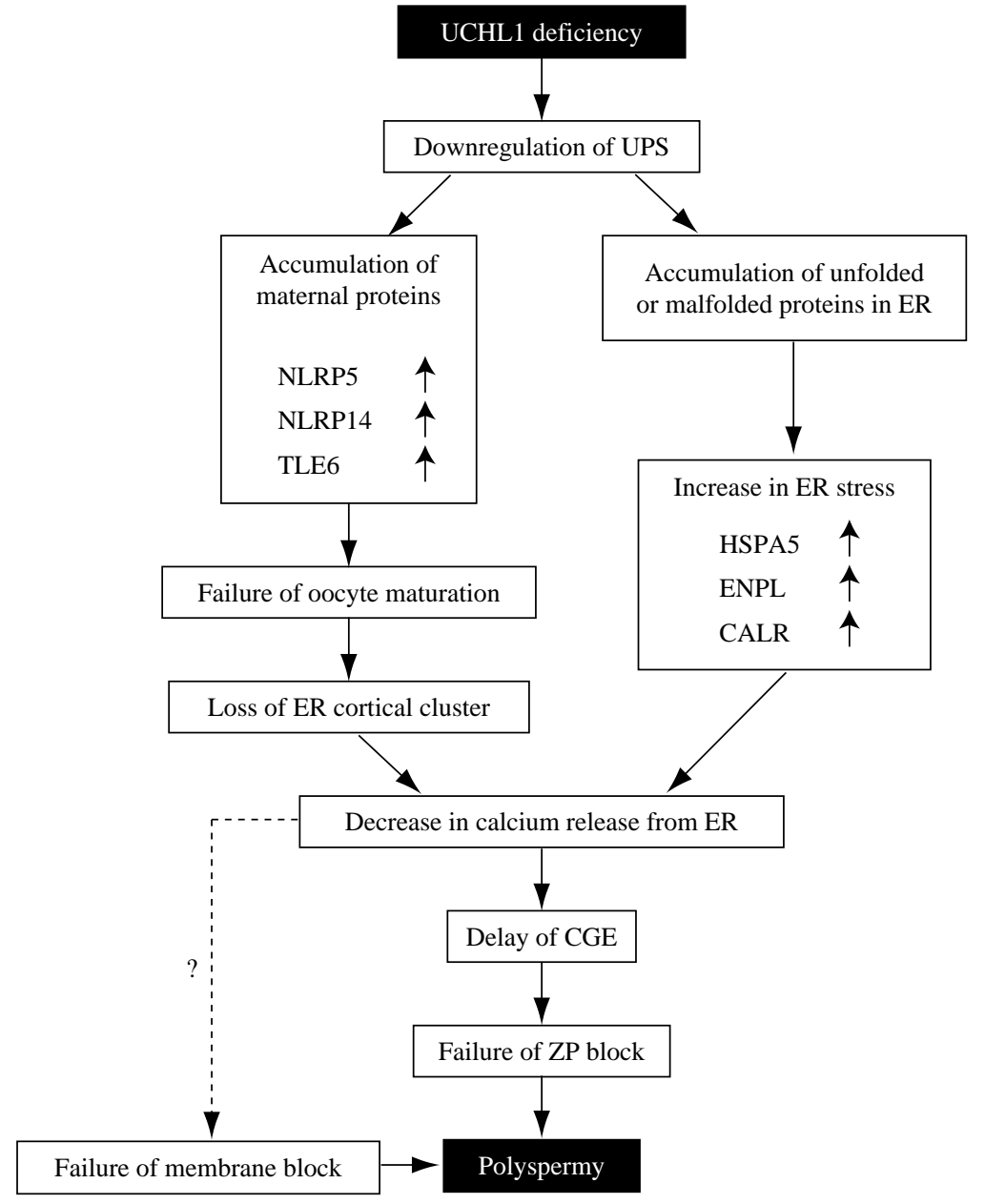

Figure 6 Consequences of UCHL1 deficiency in gad mouse ova. UCHL1 deficiency results in the downregulation of UPS and accumulation of maternal proteins in the cytoplasm and unfolded or malfolded proteins in the ER. These accumulations of protein in the cytoplasm and ER may contribute to the failure of oocyte maturation and increase in ER stress, which in turn decrease calcium release from the ER after fertilization. Thus, UCHL1 deficiency might downregulate CGE, ZP block, and membrane block and consequently induce polyspermy. UPS, ubiquitinproteasome system; $E R$, endoplasmic reticulum; CGE, cortical granule exocytosis; ZP, zona pellucida.

\section{Spectral analysis and database searching}

All MS/MS data were investigated using the Bioworks (version 3.1; Thermo Fischer) against the NCBInr mouse (Mus musculus) database. The database searches allowed for variable modification of the methionine residue (oxidation, $116 \mathrm{Da}$ ), oxidation $(\mathrm{M})$, peptide mass tolerance at $2.0 \mathrm{Da}$, and fragment mass tolerance at 1.0 Da. The identified proteins resulted from triplicate LC-MS runs for each sample and included one peptide identification. We performed label-free quantification on ovum proteins from gad mouse and wild-type mice (Kawamura et al. 2010).

\section{Antibodies}

Rabbit polyclonal anti-UCHL1 and UCHL3 antibodies were provided by Dr Kwon (Tyun-Puk University, South Korea). Mouse monoclonal anti-PGP9.5 antibody was obtained from Neuromics (Northfield, MN, USA). Rabbit polyclonal anticofilin and mouse monoclonal anti-GAPDH antibodies were purchased from Abcam. Rabbit anti-MATER antiserum was donated by the Laboratory of Cellular and Developmental Biology, NIDDK, National Institutes of Health (NIH), Bethesda, MD, USA.

\section{Western blot analysis}

Ova were subjected to SDS-PAGE using $8 \%$ gel for cofilin and $15 \%$ gel for NLRP5 proteins. The proteins were electrophoretically transferred to a PVDF membrane and blocked with 5\% nonfat dried milk in PBS-Tween 80. The membranes were incubated individually with primary antibodies (cofilin, 1:10 000; MATER, 1:15 000; UCHL1, 1:10 000; and GAPDH, $1: 10000)$ at $4{ }^{\circ} \mathrm{C}$ overnight. Then, the membrane was incubated with primary antibody against GAPDH as an internal control for $1.5 \mathrm{~h}$ and further incubated with peroxidaseconjugated secondary antibody (goat antirabbit IgG, 1:10 000-15 000; goat antisheep IgG, 1:3000; and goat antimouse IgG, 1:10000) for $1 \mathrm{~h}$ at room temperature. Immunoreactions were visualized by ECL plus (GE Healthcare Bio-Sciences, Piscataway, NJ, USA). Each immunoreactive band was quantified using Scion Image Software (NIH).

\section{Phalloidin and immunohistochemical staining}

For immunocytochemical staining, whole ova were fixed for 45 min with 4\% paraformaldehyde in PBS and permeabilized for 20 min with $0.2 \%$ Triton X-100 in PBS. Nonspecific binding of immunoglobulins was blocked by incubating with Block 
Ace for $45 \mathrm{~min}$ at room temperature. The sections were incubated with Alexa 488-phalloidin (1:2000) for $20 \mathrm{~min}$ at room temperature or with rabbit polyclonal anti-cofilin (1:10 000) antibody at $4{ }^{\circ} \mathrm{C}$ overnight. Then, they were further incubated with Alexa 488-conjugated anti-rabbit IgG for $1 \mathrm{~h}$ at room temperature.

For double-immunohistochemical staining, the sections were incubated with anti-MATER antiserum (1:10 000) and mouse monoclonal anti-UCHL1/PGP9.5 (1:40) antibody at $4{ }^{\circ} \mathrm{C}$ overnight. Then, they were further incubated with Alexa 488-conjugated anti-rabbit IgG and Alexa568-conjugated anti-mouse $\lg \mathrm{G}$ for $1 \mathrm{~h}$ at room temperature. Stained sections were observed under a confocal laser microscope (Laser Scanning Microscope 510; Carl Zeiss, Oberkochen, Germany).

\section{Transmission electron microscopy}

Isolated ova were fixed in $2.5 \%$ glutaraldehyde/ $0.1 \mathrm{M}$ phosphate buffer (PB) for $4 \mathrm{~h}$ at $4{ }^{\circ} \mathrm{C}$. After washing with PBS, they were postfixed in $1 \% \mathrm{OsO}_{4}$ in $0.1 \mathrm{M} \mathrm{PB}$ for $2 \mathrm{~h}$ at $4{ }^{\circ} \mathrm{C}$. They were then dehydrated and embedded in araldite $\mathrm{M}$. Ultrathin sections were examined under a JEOL-1010 transmission electron microscope at $80 \mathrm{kV}$.

\section{Statistical analyses}

The mean and S.D. were calculated for all data. Student's $t$-test was used for all statistical analyses. A $P$ value $<0.05$ was considered to indicate statistical significance.

\section{Declaration of interest}

The authors declare that there is no conflict of interest that could be perceived as prejudicing the impartiality of the research reported.

\section{Funding}

This study was supported by a grant-in-aid for scientific research from the Japan Society for the Promotion of Science.

\section{Acknowledgements}

We thank Takanori Nishimura and Kunihiko Naito for technical assistance. We also thank Dr Keiji Wada for providing gad mice, Dr Jungkee Kwon for providing the UCHL1 polyclonal antiserum, and Dr Jurrien Dean for providing the MATER polyclonal antiserum.

\section{References}

Bajoghli B 2007 Evolution of the Groucho/Tle gene family: gene organization and duplication events. Development Genes and Evolution 217 613-618. (doi:10.1007/s00427-007-0167-y)

Baumann O \& Walz B 2001 Endoplasmic reticulum of animal cells and its organization into structural and functional domains. International Review of Cytology 205 149-214.
Beall S, Brenner C \& Segars J 2010 Oocyte maturation failure: a syndrome of bad eggs. Fertility and Sterility 94 2507-2513. (doi:10.1016/j. fertnstert.2010.02.037)

Berridge MJ 2002 The endoplasmic reticulum: a multifunctional signaling organelle. Cell Calcium 32 235-249. (doi:10.1016/S014341600 2001823)

Buscarlet M \& Stifani S 2007 The 'Marx' of Groucho on development and disease. Trends in Cell Biology 17 353-361. (doi:10.1016/j.tcb.2007.07. 002)

Carlier MF, Laurent V, Santolini J, Melki R, Didry D, Xia GX, Hong Y, Chua NH \& Pantaloni D 1997 Actin depolymerizing factor (ADF/cofilin) enhances the rate of filament turnover: implication in actin-based motility. Journal of Cell Biology 136 1307-1322. (doi:10.1083/jcb.136. 6.1307)

Connors SA, Kanatsu-Shinohara M, Schultz RM \& Kopf GS 1998 Involvement of the cytoskeleton in the movement of cortical granules during oocyte maturation, and cortical granule anchoring in mouse eggs. Developmental Biology 200 103-115. (doi:10.1006/dbio.1998.8945)

DeRenzo C \& Seydoux G 2004 A clean start: degradation of maternal proteins at the oocyte-to-embryo transition. Trends in Cell Biology $\mathbf{1 4}$ 420-426. (doi:10.1016/j.tcb.2004.07.005)

Ducibella T \& Fissore R 2008 The roles of $\mathrm{Ca}^{2+}$, downstream protein kinases, and oscillatory signaling in regulating fertilization and the activation of development. Developmental Biology 315 257-279. (doi:10.1016/j.ydbio.2007.12.012)

Ducibella T, Kurasawa S, Duffy P, Kopf GS \& Schultz RM 1993 Regulation of the polyspermy block in the mouse egg: maturation-dependent differences in cortical granule exocytosis and zona pellucida modifications induced by inositol 1,4,5-trisphosphate and an activator of protein kinase C. Biology of Reproduction 48 1251-1257. (doi:10.1095/ biolreprod48.6.1251)

Eletto D, Dersh D \& Argon Y 2010 GRP94 in ER quality control and stress responses. Seminars in Cell \& Developmental Biology 21 479-485. (doi:10.1016/j.semcdb.2010.03.004)

Eliyahu E, Tsaadon A, Shtraizent N \& Shalgi R 2005 The involvement of protein kinase $\mathrm{C}$ and actin filaments in cortical granule exocytosis in the rat. Reproduction 129 161-170. (doi:10.1530/rep.1.00424)

Ellederova Z, Halada P, Man P, Kubelka M, Motlik J \& Kovarova H 2004 Protein patterns of pig oocytes during in vitro maturation. Biology of Reproduction 71 1533-1539. (doi:10.1095/biolreprod.104.030304)

Hatanaka Y, Nagai T, Tobita T \& Nakano M 1992 Changes in the properties and composition of zona pellucida of pigs during fertilization in vitro. Journal of Reproduction and Fertility 95 431-440. (doi:10.1530/jrf.0. 0950431)

Huo LJ, Fan HY, Zhong ZS, Chen DY, Schatten H \& Sun QY 2004 Ubiquitin-proteasome pathway modulates mouse oocyte meiotic maturation and fertilization via regulation of MAPK cascade and cyclin B1 degradation. Mechanisms of Development 121 1275-1287. (doi:10.1016/j.mod.2004.05.007)

Kawamura T, Nomura M, Tojo H, Fujii K, Hamasaki H, Mikami S, Bando Y, Kato H \& Nishimura T 2010 Proteomic analysis of laser-microdissected paraffin-embedded tissues: (1) stage-related protein candidates upon non-metastatic lung adenocarcinoma. Journal of Proteomics 73 1089-1099. (doi:10.1016/j.jprot.2009.11.011)

Kim B, Kan R, Anguish L, Nelson LM \& Coonrod SA 2010 Potential role for MATER in cytoplasmic lattice formation in murine oocytes. PLOS ONE 5 e12587. (doi:10.1371/journal.pone.0012587)

Kirkpatrick DS, Gerber SA \& Gygi SP 2005 The absolute quantification strategy: a general procedure for the quantification of proteins and posttranslational modifications. Methods 35 265-273. (doi:10.1016/j.ymeth. 2004.08.018)

Krone N, Hughes BA, Lavery GG, Stewart PM, Arlt W \& Shackleton CH 2010 Gas chromatography/mass spectrometry (GC/MS) remains a preeminent discovery tool in clinical steroid investigations even in the era of fast liquid chromatography tandem mass spectrometry (LC/MS/MS). Journal of Steroid Biochemistry and Molecular Biology 121 496-504.

Kruse U, Bantscheff M, Drewes G \& Hopf C 2008 Chemical and pathway proteomics: powerful tools for oncology drug discovery and personalized health care. Molecular and Cellular Proteomics 7 1887-1901.

Kwon J, Wang YL, Setsuie R, Sekiguchi S, Sato Y, Sakurai M, Noda M, Aoki S, Yoshikawa Y \& Wada K 2004 Two closely related ubiquitin 
C-terminal hydrolase isozymes function as reciprocal modulators of germ cell apoptosis in cryptorchid testis. American Journal of Pathology 165 1367-1374. (doi:10.1016/S0002-9440(10)63394-9)

Kwon J, Mochida K, Wang YL, Sekiguchi S, Sankai T, Aoki S, Ogura A, Yoshikawa Y \& Wada K 2005 Ubiquitin C-terminal hydrolase L-1 is essential for the early apoptotic wave of germinal cells and for sperm quality control during spermatogenesis. Biology of Reproduction $\mathbf{7 3}$ 29-35. (doi:10.1095/biolreprod.104.037077)

Li L, Baibakov B \& Dean J 2008 A subcortical maternal complex essential for preimplantation mouse embryogenesis. Developmental Cell $\mathbf{1 5}$ 416-425. (doi:10.1016/j.devcel.2008.07.010)

Massicotte L, Coenen K, Mourot M \& Sirard MA 2006 Maternal housekeeping proteins translated during bovine oocyte maturation and early embryo development. Proteomics 6 3811-3820. (doi:10.1002/ pmic.200500803)

McAvey BA, Wortzman GB, Williams CJ \& Evans JP 2002 Involvement of calcium signaling and the actin cytoskeleton in the membrane block to polyspermy in mouse eggs. Biology of Reproduction 67 1342-1352. (doi:10.1095/biolreprod67.4.1342)

Meberg PJ \& Bamburg JR 2000 Increase in neurite outgrowth mediated by overexpression of actin depolymerizing factor. Journal of Neuroscience 20 2459-2469.

Mehlmann LM, Terasaki M, Jaffe LA \& Kline D 1995 Reorganization of the endoplasmic reticulum during meiotic maturation of the mouse oocyte. Developmental Biology 170 607-615. (doi:10.1006/dbio.1995.1240)

Ohsugi M, Zheng P, Baibakov B, Li L \& Dean J 2008 Maternally derived FILIA-MATER complex localizes asymmetrically in cleavage-stage mouse embryos. Development 135 259-269. (doi:10.1242/dev.011445)

Osaka H, Wang YL, Takada K, Takizawa S, Setsuie R, Li H, Sato Y, Nishikawa K, Sun YJ, Sakurai M et al. 2003 Ubiquitin carboxy-terminal hydrolase L1 binds to and stabilizes monoubiquitin in neuron. Human Molecular Genetics 12 1945-1958. (doi:10.1093/hmg/ddg211)

Pennetier S, Perreau C, Uzbekova S, Thelie A, Delaleu B, Mermillod P \& Dalbies-Tran R 2006 MATER protein expression and intracellular localization throughout folliculogenesis and preimplantation embryo development in the bovine. BMC Developmental Biology 6 26. (doi:10. 1186/1471-213X-6-26)

Pfaffenbach KT \& Lee AS 2011 The critical role of GRP78 in physiologic and pathologic stress. Current Opinion in Cell Biology 23 150-156. (doi:10. 1016/j.ceb.2010.09.007)

Qiu Y \& Michalak M 2009 Transcriptional control of the calreticulin gene in health and disease. International Journal of Biochemistry \& Cell Biology 41 531-538. (doi:10.1016/j.biocel.2008.06.020)

Robert C, McGraw S, Massicotte L, Pravetoni M, Gandolfi F \& Sirard MA 2002 Quantification of housekeeping transcript levels during the development of bovine preimplantation embryos. Biology of Reproduction $\mathbf{6 7}$ 1465-1472. (doi:10.1095/biolreprod.102.006320)

Rutkowski DT \& Hegde RS 2010 Regulation of basal cellular physiology by the homeostatic unfolded protein response. Journal of Cell Biology 189 783-794. (doi:10.1083/jcb.201003138)

Ryu KY, Sinnar SA, Reinholdt LG, Vaccari S, Hall S, Garcia MA, Zaitseva TS, Bouley DM, Boekelheide K, Handel MA et al. 2008 The mouse polyubiquitin gene $U b b$ is essential for meiotic progression. Molecular and Cellular Biology 28 1136-1146. (doi:10.1128/MCB.01566-07)

Saigoh K, Wang YL, Suh JG, Yamanishi T, Sakai Y, Kiyosawa H, Harada T, Ichihara N, Wakana S, Kikuchi T et al. 1999 Intragenic deletion in the gene encoding ubiquitin carboxy-terminal hydrolase in gad mice. Nature Genetics 23 47-51.

Sakurai M, Sekiguchi M, Zushida K, Yamada K, Nagamine S, Kabuta T \& Wada K 2008 Reduction in memory in passive avoidance learning, exploratory behaviour and synaptic plasticity in mice with a spontaneous deletion in the ubiquitin C-terminal hydrolase L1 gene. European Journal of Neuroscience 27 691-701. (doi:10.1111/j.1460-9568.2008. 06047.x)
Sekiguchi S, Kwon J, Yoshida E, Hamasaki H, Ichinose S, Hideshima M, Kuraoka M, Takahashi A, Ishii Y, Kyuwa S et al. 2006 Localization of ubiquitin C-terminal hydrolase L1 in mouse ova and its function in the plasma membrane to block polyspermy. American Journal of Pathology 169 1722-1729. (doi:10.2353/ajpath.2006.060301)

Stricker SA 1999 Comparative biology of calcium signaling during fertilization and egg activation in animals. Developmental Biology 211 157-176. (doi:10.1006/dbio.1999.9340)

Su YQ, Sugiura K, Woo Y, Wigglesworth K, Kamdar S, Affourtit J \& Eppig J J 2007 Selective degradation of transcripts during meiotic maturation of mouse oocytes. Developmental Biology 302 104-117. (doi:10.1016/j. ydbio.2006.09.008)

Sun QY 2003 Cellular and molecular mechanisms leading to cortical reaction and polyspermy block in mammalian eggs. Microscopy Research and Technique 61 342-348. (doi:10.1002/jemt.10347)

Susor A, Ellederova Z, Jelinkova L, Halada P, Kavan D, Kubelka M \& Kovarova H 2007 Proteomic analysis of porcine oocytes during in vitro maturation reveals essential role for the ubiquitin C-terminal hydrolaseL1. Reproduction 134 559-568. (doi:10.1530/REP-07-0079)

Susor A, Liskova L, Toralova T, Pavlok A, Pivonkova K, Karabinova P, Lopatarova M, Sutovsky P \& Kubelka M 2010 Role of ubiquitin C-terminal hydrolase-L1 in antipolyspermy defense of mammalian oocytes. Biology of Reproduction 82 1151-1161. (doi:10.1095/biolreprod.109.081547)

Tan YY, Zhou HY, Wang ZQ \& Chen SD 2008 Endoplasmic reticulum stress contributes to the cell death induced by UCH-L1 inhibitor. Molecular and Cellular Biochemistry 318 109-115. (doi:10.1007/s11010-008-9862-x)

Tashiro F, Kanai-Azuma M, Miyazaki S, Kato M, Tanaka T, Toyoda S, Yamato E, Kawakami H, Miyazaki T \& Miyazaki J 2010 Maternal-effect gene Ces5/Ooep/Moep19/Floped is essential for oocyte cytoplasmic lattice formation and embryonic development at the maternal-zygotic stage transition. Genes to Cells 15 813-828. (doi:10.1111/j.1365-2443. 2010.01420.x)

Tsaadon A, Eliyahu E, Shtraizent N \& Shalgi R 2006 When a sperm meets an egg: block to polyspermy. Molecular and Cellular Endocrinology 252 107-114. (doi:10.1016/j.mce.2006.03.037)

Wassarman PM \& Litscher ES 2008 Mammalian fertilization: the egg's multifunctional zona pellucida. International Journal of Developmental Biology 52 665-676. (doi:10.1387/ijdb.072524pw)

Wilkinson KD, Lee KM, Deshpande S, Duerksen-Hughes P, Boss JM \& Pohl J 1989 The neuron-specific protein PGP 9.5 is a ubiquitin carboxylterminal hydrolase. Science 246 670-673. (doi:10.1126/science. 2530630)

Wilson PO, Barber PC, Hamid QA, Power BF, Dhillon AP, Rode J, Day IN, Thompson RJ \& Polak JM 1988 The immunolocalization of protein gene product 9.5 using rabbit polyclonal and mouse monoclonal antibodies. British Journal of Experimental Pathology 69 91-104.

Yoshida H 2007 ER stress and diseases. FASEB Journal 274 630-658.

Zhang P, Dixon M, Zucchelli M, Hambiliki F, Levkov L, Hovatta O \& Kere J 2008 Expression analysis of the NLRP gene family suggests a role in human preimplantation development. PLOS ONE 3 e2755. (doi:10.1371/ journal.pone.0002755)

Zhang P, Ni X, Guo Y, Guo X, Wang Y, Zhou Z, Huo R \& Sha J 2009 Proteomic-based identification of maternal proteins in mature mouse oocytes. BMC Genomics 10 348. (doi:10.1186/1471-2164-10-348)

Received 19 April 2011

First decision 2 June 2011

Revised manuscript received 6 December 2011

Accepted 5 January 2012 